\title{
Recent Therapeutic Options in Cancer Therapy
}

\author{
Rameena Aruza ${ }^{1 *}$, Mavera Lucino ${ }^{2}$ and Nelden Shanel ${ }^{3}$ \\ ${ }^{1}$ Oncology unit, Medical Sciences, Madrez University, Sao Paulo, Brazil \\ ${ }^{2}$ Pharmacology unit, Medical Sciences, Madrez University, Sao Paulo, Brazil \\ ${ }^{3}$ Radiotherapy unit, Medical Sciences, Madrez University, Sao Paulo, Brazil \\ *Corresponding author: Rameena Aruza, Oncology unit, Medical Sciences, Madrez University, Sao Paulo, Brazil
}

\begin{tabular}{|c|c|}
\hline ARTICLE INFO & ABSTRACT \\
\hline Received: July 06, 2021 & $\begin{array}{l}\text { Nanoparticles are used in several fields and its importance in medical field has } \\
\text { proven to be beneficial. They have proven to be useful in cancer treatment due to their }\end{array}$ \\
\hline Published: 㗀 July 13, 2021 & $\begin{array}{l}\text { quick target delivery and also due to their effectiveness in penetrating the cancer cells. } \\
\text { They have also proven to be beneficial in psychotic conditions as drugs like haloperidol }\end{array}$ \\
\hline
\end{tabular}

cino, Nelden Shanel. Recent Therapeutic Options in Cancer Therapy. Biomed J Sci \& Tech Res 37(2)-2021. BJSTR. MS.ID.005961.

Keywords: Cancer; Nanotechnology; Target Delivery; Drugs

\section{Introduction}

Nanotechnology is already widely applicable in medical field by their various drug delivery systems, in the principle of magnetic resonance in cancer treatments and cellular biology [1-3]. Researchers in nanotechnology have carefully monitored and applied its use in creating the best medical and biological equipment's and devices so as to be beneficial for patient care [46]. This review briefly details the role of nanoparticles in general medicine and then focusing on its application in treating patients with brain and lung cancers [7-9].

\section{Role of Nanotechnology in Medicine}

Nanoparticles are used successfully in the deliverance of basic physical substances such as heat, light, and other substances to the target cell of interest $[10,11]$. This has been beneficial in using nanotechnology as a treatment option for managing cancers [12]. The nanoparticles enter the target cancer cell and produce a cellular arrest and thereby inhibiting the uncontrolled tumor growth [13]. This further interrupt the proto-oncogenes and tumor suppressor genes causing an abrupt interference of the tumor growth cycle [14]. The highly effective tumor cell penetrance property of the nanoparticles has been proven to be beneficial in combatting the tumor cell biology (Figure 1). The adverse effects in the application of nanotechnology in cancer care treatment is very minimal and hence has shown to be widely applicable[15]. The role of gapmer design in downregulating the cancer cells has also been proven recently [16]. This design model has shown to increase the binding capacity of the nanoparticles to the cancer cells and then downregulates the entire tumor environment [17-19].

The role of nanotechnology in treating brain and lung cancers has been formulated with the LMP in vivo and in vitro levels [20-22]. The LMP formulations reach high levels in these cancer types, hence providing a better chemical and physical stability. These properties further enhance the overhaul performance of nanoparticles effect in brain and lung cancers. The antisense oligonucleotide combination with lipid subunit of nanoparticles produces quaternary aminetertiary cation lipid complex. This complex is very efficient and also cost-effective in cancer therapy [23-25]. Nanoparticles can be combined with various elements, however its combination with polymers and lipid component seems to be the most effective formula [26]. This is mainly attributed to its high bioavailability, compatibility, and also higher safety level. These combinations are used in treating varying cancer types, especially the brain and lung cancers [27]. 


\section{Improving cancer treatment}
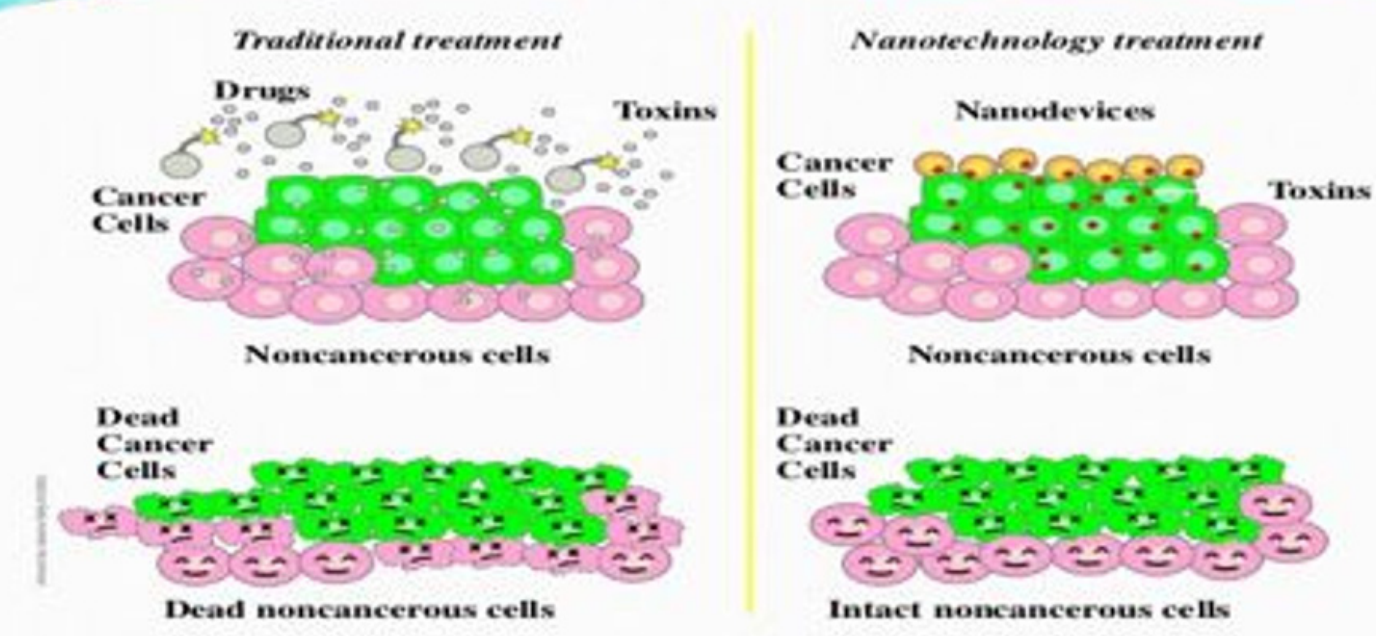

Figure 1: A schematic representation of the nanoparticle effect. The colloidal nanoparticles are accumulated in tumors due to their higher vascular endothelial penetrance.

\section{Role of Nanoparticles in Brain Cancer Treatment}

The role of nanoparticles as a therapeutic option in psychosis is well versed. The anti-psychotic drug, haloperidol develops blocks at neuronal level and thereby ensures slow release of the pharmaceutical substances [28]. This has been beneficial as the relevance of psychosis in modern society has been exponential raising [29]. The dendrimers further alter and induced as nanoparticles. The other popular anti-psychotic medication, risperidone is used effectively in treating schizophrenia [30]. As both these basic and common anti-psychotic drugs are already in treatment plans for psychosis, we now move to the role of nanoparticles in treating brain cancers [31]. Brain tumors are mostly glial based. These are classified as Gliomas by the World Health Organization (WHO). Based on its histological features they are further subtyped into grad 1 to 4 . Grade 1 been most mild and grade 4 been most aggressive [32-34]. The application of nanotechnology in treating brain cancers has been limited even though there is abundance of nanoparticles available in the market. This is mainly attributed to the aggressiveness of the brain tumor and also the limitations of nanoparticles in arresting the cell cycle of the tumor. However, when nanoparticle is combined with other chemotherapeutic drugs they produce beneficial effects to the patients by reducing the extent of side effects. This occurs due to the in vivo and in vitro effects of nanoparticles in a tumor environment $[35,36]$.

The application of gold nanoparticles has been effective and productive in brain target drug delivery. The gold electrons are conducted on the metal surface followed by light excitation [37]. The Serine-arginine-leucine (SRL) modified dendrimers produce a high transfusion rate and a low toxicity level. These effects have limitations as they can only be applied in less aggressive forms of brain cancers [38]. In Glioblastoma multiforme, a form of brain tumor, is aggressive and makes it difficult for the procedure to turn effective. Fibrin binding peptide can be induced to treat this case [39]. Studies are still underway in applying polymer, lips, and microbubbles form of nanoparticles to treat brain tumors [40]. These forms have shown lower toxicity compared to other forms of nanoparticles. This application is important as there needs to be an equilibrium between the drug delivery and adverse effects during treatment of aggressive forms of brain cancers [41].

\section{Role of Nanoparticles in Lung Cancer Treatment}

Lung cancers are mainly adenocarcinomas. These are followed by squamous cells carcinomas and neuroendocrine cancers [42]. The origin of lung cancer has been cited mainly due to its molecular alterations and environmental-host imbalances [43]. The overexpression of an anti-apoptotic gene, Bcl-2 has shown to be a very important cause for lung cancer origin. The expression of Bcl-2 has been controlled by the antisense oligonucleotides (ASOs) therapy [44]. But this control level has been minimal due to problems in tumor-particle binding ratio, immune nature if oligonucleotide and low in vitro and in vivo nanoparticle concentration. This has led to the demand of lipid nanoparticles which can increase the overall nuclease stability and the circulation time of such oligonucleotides $[45,46]$. The lipid nanoparticles alter the tumor microenvironment by altering the cell cycle, inhibiting proto-oncogenes, and enhancing cell cycle arrest factors [47]. miR-21 plays an essential role in regulating the propagation of tumor and cancer. QTsome nanoparticles are ideal for inducing strong dosage of the therapy 
without affecting the sensitivity and increasing the invasion pace [48]. However, extensive research is still required in order to use nanoparticles more commonly in lung cancer treatment.

\section{Conclusion}

The role of nanotechnology in patient care has been growing every year. The success of these particles has been attributed to its fast drug deliverance systems and its ability to interrupt the cancer microenvironment. The beneficial effects of nanoparticles in treating psychosis have laid a foundation on which its physical and chemical nature cane be more explored. This holds true for treating cancers especially of the brain and the lungs.

\section{Acknowledgement}

Nil.

\section{Conflicts of Interest}

Nil.

\section{Financial Aid}

No grants/ external fund received.

\section{Author Contributions}

All authors were involved in concept, design, data collection, formulation, writing the manuscript, editing and approval of final manuscript.

\section{References}

1. Bray F, Ferlay J, Soerjomataram I, Siegel RL, Torre LA, et al. (2018) Global cancer statistics 2018: GLOBOCAN estimates of incidence and mortality worldwide for 36 cancers in 185 countries. CA Cancer J Clin 68: 394-424.

2. Hu J, Huang $W$, Huang $S$, ZhuGe $Q$ Jin $K$, et al. (2016) Magnetically active Fe304 nanorods loaded with tissue plasminogen activator for enhanced thrombolysis. Nano Research 9: 2652-2661.

3. Huang L, Hu J, Huang S, Wang B, Siaw Debrah F, etal. (2017) Nanomaterial Applications for Neurological Diseases and Central Nervous System Injury. Prog Neurobiol 157: 29-48.

4. Tran S, Degiovanni PJ, Piel B, Rai PJC (2017) Cancer nanomedicine: A review of recent success in drug delivery 6(1): 44.

5. Huang D, Wu K, Zhang Y, Ni Z, Zhu X, et al. (2019) Recent Advances in Tissue plasminogen activator-based nano thrombolysis for ischemic stroke 58: 159 .

6. Hu J, Huang S, Zhu L, Huang W, Zhao Y, et al. (2018) Tissue Plasminogen Activator-Porous Magnetic Microrods for Targeted Thrombolytic Therapy after Ischemic Stroke. ACS Appl Mater Interfaces 10(39): 32988-32997.

7. Chaturvedi VK, Singh A, Singh VK, Singh MP (2019) Cancer Nanotechnology: A New Revolution for Cancer Diagnosis and Therapy. Current drug metabolism 20: 416-429.

8. Ye F, Zhao Y, El Sayed R, Muhammed M, Hassan MJNT (2018) Advances in nanotechnology for cancer biomarkers. ScienceDirect 18: 103-23.

9. Bharali DJ, Mousa SA (2010) Emerging nanomedicines for early cancer detection and improved treatment: Current perspective and future promise. Pharmacology \& therapeutics 128: 324-335.
10. Kim D, Jeong YY, Jon SJAN (2010) A Drug-Loaded Aptamer? Gold Nanoparticle Bioconjugate for Combined CT Imaging and Therapy of Prostate Cancer. ACS pub 4: 3689-3696.

11. Akhter S, Ahmad I, Ahmad MZ, Ramazani F, Singh A, et al. (2013) Nanomedicines as cancer therapeutics: Current status. Current cancer drug targets 13: 362-378.

12. Wang J, Sui M, Fan W (2010) Nanoparticles for tumor targeted therapies and their pharmacokinetics. Current drug metabolism 11: 129-141.

13. Popescu RC, Fufă MO, Grumezescu AM (2015) Metal-based Nanosystem for diagnosis. Romanian journal of morphology and embryology 56: 635-649.

14. Singh R (2019) Nanotechnology based therapeutic application in cancer diagnosis and therapy. 3 Biotech 9(11): 415.

15. Wan X, Song Y, Song N, Li J, Yang L, et al. (2016) The preliminary study of immune superparamagnetic iron oxide nanoparticles for the detection of lung cancer in magnetic resonance imaging. Carbohydrate research 419: 33-40.

16. Sherry AD, Woods M (2008) Chemical exchange saturation transfer contrast agents for magnetic resonance imaging. Annual review of biomedical engineering 10: 391-411.

17. Umakanthan S, Chattu VK, Kalloo S (2019) Global epidemiology, risk factors, and histological types of ovarian cancers in Trinidad. J Family Med Prim Care 8(3): 1058-1064.

18. Jafari A, Salouti M, Shayesteh SF, Heidari Z, Rajabi AB, et al. (2015) Synthesis and characterization of Bombesin-superparamagnetic iron oxide nanoparticles as a targeted contrast agent for imaging of breast cancer using MRI. Nanotechnology 26: 075101.

19. Stocke NA, Meenach SA, Arnold SM, Mansour HM, Hilt JZ (2015) Formulation and characterization of inhalable magnetic nanocomposite microparticles (MnMs) for targeted pulmonary delivery via spray drying. International journal of pharmaceutics 479: 320-328.

20. Garrigue P, Tang J, Ding L, Bouhlel A, Tintaru A, et al. (2018) Selfassembling supramolecular dendrimer nanosystem for PET imaging of tumors. Proceedings of the National Academy of Sciences of the United States of America 115(45): 11454-1149.

21. Ji T, Zhao Y, Wang J, Zheng X, Tian Y, et al. (2013) Tumor Fibroblast Specific Activation of a Hybrid Ferritin Nanocage-Based Optical Probe for Tumor Microenvironment Imaging. Small 9: 2427-2431.

22. Parungo CP, Ohnishi S, De Grand AM, Laurence RG, Soltesz EG, et al. (2004) In vivo optical imaging of pleural space drainage to lymph nodes of prognostic significance. Annals of surgical oncology 11: 1085-1092.

23. Gao X, Cui Y, Levenson RM, Chung LW, Nie S (2004) In vivo cancer targeting and imaging with semiconductor quantum dots. Nature biotechnology 22: 969-976.

24. Dubertret B, Skourides P, Norris DJ, Noireaux V, Brivanlou AH, et al (2002) In vivo imaging of quantum dots encapsulated in phospholipid micelles. Science 298: 1759-1762.

25. Zhang Y, Yang H, An X, Wang Z, Yang X, et al. (2020) Controlled Synthesis of $\mathrm{Ag}(2) \mathrm{Te} @ \mathrm{Ag}(2) \mathrm{S}$ Core-Shell Quantum Dots with Enhanced and Tunable Fluorescence in the Second Near-Infrared Window. Small 16: e2001003.

26. Hirsch LR, Stafford RJ, Bankson JA, Sershen SR, Rivera B, et al. (2003) Nanoshell-mediated near-infrared thermal therapy of tumors under magnetic resonance guidance. Proceedings of the National Academy of Sciences of the United States of America 100(23): 13549-13554.

27. Loo C, Lin A, Hirsch L, Lee MH, Barton J, et al. (2004) Nanoshell-enabled photonics-based imaging and therapy of cancer. Technology in cancer research \& treatment 3(1): 33-40. 
28. Nunes T, Pons T, Hou X, Van Do K, Caron B, et al. (2019) Pulsedlaser irradiation of multifunctional gold nanoshells to overcome trastuzumab resistance in HER2-overexpressing breast cancer. Journal of experimental \& clinical cancer research 38: 306.

29. Fu N, Hu Y, Shi S, Ren S, Liu W, et al. (2018) Au nanoparticles on two-dimensional $\operatorname{MoS}(2)$ nanosheets as a photoanode for efficient photoelectrochemical miRNA detection. The Analyst 143: 1705-1712.

30. Fu F, Li L, Luo Q, Li Q, Guo T, et al. (2018) Selective and sensitive detection of lysozyme based on plasmon resonance light-scattering of hydrolyzed peptidoglycan stabilized-gold nanoparticles. The Analyst. 143: 11331140 .

31. Shrivas K, Nirmalkar N, Thakur SS, Deb MK, Shinde SS, et al. (2018) Sucrose capped gold nanoparticles as a plasmonic chemical sensor based on non-covalent interactions: Application for selective detection of vitamins $B_{1}$ and $B_{6}$ in brown and white rice food samples. Food chemistry 250: $14-21$.

32. Das PM, Bast RC (2008) Early detection of ovarian cancer. Biomark Med 2: 291-303.

33. Kuk C, Kulasingam V, Gunawardana CG, Smith CR, Batruch I, et al. (2009) Mining the ovarian cancer ascites proteome for potential ovarian cancer biomarkers. Mol Cell Proteomics 8(4): 661-669.

34. Fredolini C, Meani F, Luchini A, Zhou W, Russo P, et al. (2010) Investigation of the ovarian and prostate cancer peptidome for candidate early detection markers using a novel nanoparticle biomarker capture technology. AAPS J 12: 504-518.

35. Di Michele M, Marcone S, Cicchillitti L, Della Corte A, Ferlini C, et al. (2010) Glycoproteomics of paclitaxel resistance in human epithelial ovarian cancer cell lines: Towards the identification of putative biomarkers. J Proteomics 73: 879-898.

36. Geho DH, Liotta LA, Petricoin EF, Zhao W, Araujo RP (2006) The amplified peptidome: The new treasure chest of candidate biomarkers. Current Opinion in Chemical Biology 10: 50-55.

37. Zhou M, Lucas DA, Chan KC, Issaq HJ, Petricoin EF, et al. (2004) An investigation into the human serum "interactome". Electrophoresis 25 $1289-1298$.

38. Merrell K, Southwick K, Graves SW, Esplin MS, Thulin CD (2005) Analysis of Low-Abundance, Low-Molecular-Weight Serum Proteins Using Mass Spectrometry. J Biomol Tech 15: 238-248.

ISSN: 2574-1241

DOI: 10.26717/BJSTR.2021.37.005961

Rameena Aruza. Biomed J Sci \& Tech Res

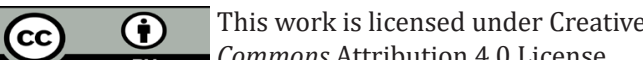

Submission Link: https://biomedres.us/submit-manuscript.php
39. Geho DH, Jones CD, Petricoin EF, Liotta LA (2006) Nanoparticles: Potential biomarker harvesters. Current opinion in chemical biology 10 : 56-61.

40. Luchini A, Fredolini C, Espina BH, Meani F, Reeder A, et al. (2010) Nanoparticle technology: Addressing the fundamental roadblocks to protein biomarker discovery. Current molecular medicine 10(2): 133141.

41. Terracciano R, Pasqua L, Casadonte F, Frascà S, Preianò M, et al. (2009) Derivatized mesoporous silica beads for MALDI-TOF MS profiling of human plasma and urine. Bioconjugate chemistry 20: 913-923.

42. Umakanthan Srikanth, Maryann M Bukelo (2021) Concise genetic profile of lung carcinoma. Postgraduate medical journal.

43. Longo C, Patanarut A, George T, Bishop B, Zhou W, et al. (2009) Coreshell hydrogel particles harvest, concentrate and preserve labile low abundance biomarkers. PloS one 4: e4763.

44. Gaspari M, Ming Cheng Cheng M, Terracciano R, Liu X, Nijdam AJ, et al. (2006) Nanoporous surfaces as harvesting agents for mass spectrometric analysis of peptides in human plasma. Journal of proteome research 5 : 1261-1266.

45. Terracciano R, Gaspari M, Testa F, Pasqua L, Tagliaferri P, et al. (2006) Selective binding and enrichment for low-molecular weight biomarker molecules in human plasma after exposure to nanoporous silica particles. Proteomics 6(11): 3243-3250.

46. Najam-ul-Haq M, Rainer M, Szabó Z, Vallant R, Huck CW, et al. (2007) Role of carbon nanomaterials in the analysis of biological materials by laser desorption/ionization-mass spectrometry. Journal of biochemical and biophysical methods 70(2): 319-328.

47. Xu S, Li Y, Zou H, Qiu J, Guo Z, et al. (2003) Carbon nanotubes as assisted matrix for laser desorption/ionization time-of-flight mass spectrometry. Analytical chemistry 75: 6191-6195.

48. Jones M, Leroux J (1999) Polymeric micelles - a new generation of colloidal drug carriers. European journal of pharmaceutics and biopharmaceutics 48(2): 101-111.

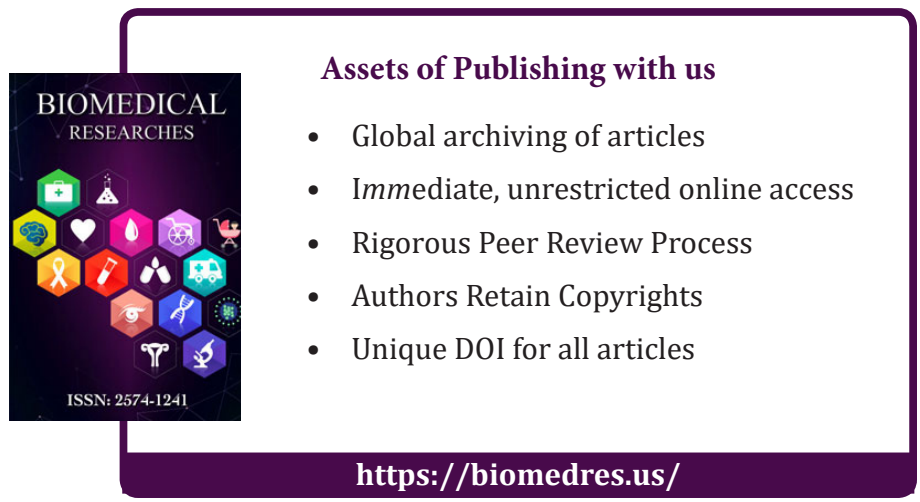

